\title{
Lingual Nerve Morbidity and Mandibular Third Molar Surgery: A Prospective Study
}

\author{
Zaid H. Baqain Ashraf Abukaraky Yazan Hassoneh Faleh Sawair \\ Department of Oral and Maxillofacial Surgery, Oral Medicine, Oral Pathology and Periodontology, Faculty of \\ Dentistry, University of Jordan, Amman, Jordan
}

\section{Key Words}

Lingual nerve $\cdot$ Morbidity $\cdot$ Surgery $\cdot$ Dental

\begin{abstract}
Objective: The objective of this study was to estimate the frequency of postoperative lingual nerve (LN) impairment after the surgical removal of mandibular third molars (M3) and to identify potential risk indicators. Subjects and Methods: A prospective cohort study involving 321 subjects who had 443 mandibular M3 surgically extracted at the University Hospital, Amman, Jordan. Predictor variables were categorized as patient-, anatomy- and operation-specific. The outcome variable was the presence or absence of $L N$ impairment. Bivariate and multivariate analyses were performed to identify independent predictors. Results: The prevalence of temporary LN hypoesthesia was $2.5 \%$ and all 11 cases resolved within 6 months. Factors that predicted LN injury by univariate analysis were horizontal and mesioangular tooth angulation, bone removal, tooth sectioning, longer operations, lingual flap retraction and bleeding into the socket. In the multivariate logistic regression model, lingual flap retraction $(p=0.002, O R=26.790)$ and bleeding into the socket $(p=0.044, O R=4.918)$ were the independent predictors. Conclusion: Operative variables were the main predictors of temporary LN damage.

Copyright $\odot 2009$ S. Karger AG, Basel
\end{abstract}

(C) 2009 S. Karger AG, Basel

1011-7571/10/0191-0028\$26.00/0

Fax +4161306 1234

E-Mail karger@karger.ch

www.karger.com
Accessible online at: www.karger.com/mpp

\section{Introduction}

Extraction of the mandibular third molars (M3) is not only one of the most frequently performed procedures in oral and maxillofacial surgery, but is a common surgical event [1]. Among the most serious complications of this procedure is lingual sensory impairment, which has serious medical and legal implications [2]. In previous studies, the prevalence of damage to the lingual nerve (LN) varied from almost 0\% [3] to 23\% [4]. Several etiological factors have been proposed for $\mathrm{LN}$ damage in mandibular M3 surgery: trauma from an inferior alveolar nerve injection, the incision, intubation and general anesthesia, lingual flap retraction, bone removal and instrumentation, tooth sectioning, tooth elevation and suturing $[5,6]$. Morbidity may also be related to inadequate experience of the operator [7]. Lingual retraction is the most debated reported risk factor that causes LN morbidity; the reported disadvantages of lingual retraction with retractors include the inadequate size of the instrument, its sharp edges, traumatization of the nerve and induction of a stretchtype injury [8].

Sunderland [9] proposed a classification summarizing the mechanism of peripheral nerve injuries, and these are: compression injuries (neurapraxia), severe compression (axonotmesis), stretch injury, sectioning of the nerve trunk (neurotmesis) and other injuries. Unlike the infe- 
rior alveolar nerve, a nerve housed in a bony canal, serious injury to the LN has less opportunity to heal as the LN tends to retract and become trapped within scar tissue, requiring surgical intervention in many instances $[7,10]$.

This study is a prospective analysis of the occurrence of LN impairment after the surgical removal of mandibular M3. The aims were to determine the frequency of postoperative sensory impairment, the duration of sensory loss, and to investigate patient, anatomic and operative variables based on multivariate regression technique predictive of the postoperative alteration of sensation.

\section{Subjects and Methods}

\section{Patients}

This prospective study was conducted at the Division of Oral and Maxillofacial Surgery, University of Jordan Hospital, Amman, between June 2006 and January 2008. Approval for the study was obtained from the institution's ethics committee and informed consent was obtained from each patient. One inclusion criterion was the use of a buccal mucoperiosteal flap. Erupted teeth and those associated with pathology were excluded. Patients were randomly treated by specialists (Z.H.B. and A.A.) and residents. A total of 443 mandibular M3 extractions were performed on 321 patients. Mean age was 22 years; 229 patients were females and the remaining 92 males. 143 patients had mesioangular impactions, while 185 patients had partially bony impacted M3.

The predictor variables for the study were classified as patient-, anatomy- and operation-specific variables. Patient variables included age and gender; the former was analyzed as a continuous variable. Anatomic variables included level of impaction (soft tissue, partial bony or total bony) and angulation. The operation-specific variables included type of anesthesia (local anesthesia alone or local anesthesia and sedation), bone removal, lingual flap retraction, excessive bleeding into the socket and the surgeon's experience (junior resident, senior resident or specialist); the operation time was analyzed as a continuous measure, and the $\mathrm{M} 3$ side, right or left $(\mathrm{R} / \mathrm{L})$, in relation to the handedness of the operator $(\mathrm{R} / \mathrm{L})$. The outcome variable was the presence of postoperative lingual neurosensory deficit.

\section{Surgical Procedure}

All procedures were performed with the same surgical instruments under local anesthesia using local tissue infiltration and inferior alveolar nerve block (2\% lidocaine with 1:100,000 adrenaline) with or without sedation given intravenously (midazolam). Antibiotics (1 g co-amoxiclav) and steroids (8 mg dexamethasone) were administered intravenously at induction. A buccal mucoperiosteal flap was employed; ostectomy, when required, was performed with a round bur in a straight handpiece with sterile water irrigation; for tooth sectioning, a fissure bur and a straight elevator were used. The lingual split technique was not used. The use of lingual retraction had to be approved by the senior member of the team when there was a need for bone removal distal to the M3 or the crown of the M3 needed to be sectioned.
A Howarth periosteal elevator $[5,8]$ was carefully inserted at the lingual rim of the retromolar trigone and was not pushed deep down along the lingual aspect. The socket was then inspected, curetted and irrigated with normal saline, the flap repositioned and sutured with a resorbable suture on a reverse cutting needle. The elapsed time from making the incision to finishing the sutures was noted. A gauze pack was pressed against the surgical site for the patient to bite on. The surgical sites of all patients were reviewed 7 days after the operation by one of the specialists (Z.H.B. and A.A.) or residents, who had no access to the preoperative or operation data. The patients were asked to report and describe any subjective alteration in lingual sensation; sensory deficit was also detected by clinical examination, carried out bilaterally. Tactile perception of the following stimuli was assessed: light touch sensation using a wisp of cotton wool, pin prick with a point of dental probe and two-point discrimination [5, 11, 12]. The impairment was classified as dysesthesia (painful sensation triggered by nonnoxious stimuli), hypoesthesia (diminished sensation), or anesthesia (absence of sensation) [13]. Thermal sensation and taste were not evaluated. Any positive results were recorded, and these patients were seen again on a monthly basis with the examiner blinded to the results of preceding examination(s).

\section{Statistical Analysis}

Statistical analysis was performed using SPSS for Windows release 15.0 (SPSS Inc., Chicago, Ill., USA). Univariate analyses using the $\chi^{2}$ test and the independent samples $t$ test were used to determine the associations between the different predictor variables and sensory impairment 1 week after surgery. In the analyses, this impairment of LN was considered as the variable. Fisher's exact test was used when only 2 subgroups were compared because the expected numbers of patients within the subgroups were small. Differences at the $5 \%$ level were accepted as significant. Important relationships between the different significant predictors were tested using the $\chi^{2}$ test and the independent samples $t$ test. Forward stepwise multivariate logistic regression analysis was then employed to control for potential confounding variables and to calculate the ORs and confidence limits for potential independent predictors of nerve injury. Biologically relevant variables (age and gender) and variables that had $\mathrm{p}<0.20$ in the initial analyses were entered into the logistic regression model as independent variables. Regarding the stepwise analysis, 0.05 was the cut-off level for including and 0.10 was the cut-off level for excluding a variable in the analysis.

\section{Results}

The patients' profiles are given in table 1. The mean time to complete surgery was $11.4 \mathrm{~min}$. On the first postoperative visit, LN hypoesthesia was diagnosed in 11 of the 443 surgical extractions, 1 case was bilateral. Neurosensory function was fully restored within 6 months (table 2) without postoperative therapy. Univariate analysis showed that hypoesthesia was significantly affected by 6 factors given in table 3 . The mean operation time for pa- 
Table 1. Profile of 443 surgical M3 extractions

\begin{tabular}{|c|c|c|}
\hline & Category & Number \\
\hline \multicolumn{3}{|l|}{ Patient variables } \\
\hline \multirow[t]{2}{*}{ Gender } & male & $92(28.7)$ \\
\hline & female & $229(71.3)$ \\
\hline \multirow[t]{3}{*}{ Age, years } & mean $\pm \mathrm{SD}$ & $22.0 \pm 5.49$ \\
\hline & median & 21.0 \\
\hline & range & $16-66$ \\
\hline \multicolumn{3}{|l|}{ Dental variables } \\
\hline \multirow[t]{2}{*}{ M3 side } & right & $245(55.3)$ \\
\hline & left & $198(44.7)$ \\
\hline \multirow[t]{4}{*}{ Angulation } & mesioangular & $198(44.7)$ \\
\hline & distoangular & $73(16.5)$ \\
\hline & vertical & $132(29.8)$ \\
\hline & horizontal & $40(9.0)$ \\
\hline \multirow[t]{3}{*}{ Level of impaction } & soft tissue impaction & $146(33.0)$ \\
\hline & partial bony impaction & $256(57.8)$ \\
\hline & total bony impaction & $41(9.3)$ \\
\hline \multirow[t]{4}{*}{ Number of roots } & 1 & $20(4.5)$ \\
\hline & 2 & $173(39.1)$ \\
\hline & multiple & $42(9.5)$ \\
\hline & missing data & $208(47)$ \\
\hline \multirow{3}{*}{ Shape of roots } & straight & $93(21.0)$ \\
\hline & curved & $131(29.6)$ \\
\hline & missing data & $219(49.4)$ \\
\hline \multicolumn{3}{|l|}{ Operative variables } \\
\hline \multirow[t]{2}{*}{ Anesthesia } & local & $52(11.7)$ \\
\hline & local + sedation & $391(88.3)$ \\
\hline \multirow[t]{2}{*}{ Bone removal } & no & $139(31.4)$ \\
\hline & yes & $304(68.6)$ \\
\hline \multirow[t]{3}{*}{ Tooth sectioning } & no & $304(68.6)$ \\
\hline & yes & $122(27.5)$ \\
\hline & missing data & $17(3.8)$ \\
\hline \multirow{3}{*}{$\begin{array}{l}\text { Lingual flap } \\
\text { retraction }\end{array}$} & no & $299(67.5)$ \\
\hline & yes & $110(24.8)$ \\
\hline & missing data & $34(7.7)$ \\
\hline \multirow{3}{*}{$\begin{array}{l}\text { Bleeding into } \\
\text { the socket }\end{array}$} & no & $301(67.9)$ \\
\hline & yes & $13(2.9)$ \\
\hline & missing data & $129(29.1)$ \\
\hline \multirow{3}{*}{$\begin{array}{l}\text { Operation time, } \\
\text { min }\end{array}$} & mean $\pm S D$ & $11.4 \pm 9.49$ \\
\hline & median & 9.0 \\
\hline & range & $2-60$ \\
\hline \multirow[t]{3}{*}{ Surgeon } & 1 st- or 2 nd-year resident & $101(22.8)$ \\
\hline & 3 rd- or 4 th-year resident & $203(45.8)$ \\
\hline & specialist & $139(31.4)$ \\
\hline
\end{tabular}

Values in parentheses denote percentages.

tients with hypoesthesia was $21.2 \pm 8.16$ min compared to $11.2 \pm 9.39 \mathrm{~min}$ for normal subjects $(\mathrm{p}=0.001)$. Multivariate regression analysis identified lingual flap retraction and bleeding into the socket as independent predictors of hypoesthesia (table 4). Patients were 23 times
Table 2. Prevalence of lingual hypoesthesia at specific time intervals after M3 surgery

\begin{tabular}{lc}
\hline Time after surgery & Lingual hypoesthesia \\
\hline 1 week & $11(2.5)$ \\
1 month & $10(2.3)$ \\
2 months & $9(2.0)$ \\
3 months & $7(1.6)$ \\
4 months & $6(1.4)$ \\
5 months & $3(0.7)$ \\
6 months & $0(0.0)$ \\
\hline
\end{tabular}

Values in parentheses denote percentages.

more likely to sustain transient neurosensory damage to the LN when lingual tissues were retracted, and they had a 7 times greater risk with significant bleeding into the socket during surgery. Of the 110 patients in whom lingual retraction was performed, 10 (9.1\%) developed lingual hypoesthesia, whereas only $1(0.3 \%)$ of the 299 patients who had no retraction developed hypoesthesia. A lingual flap was more commonly retracted with horizontal (55.3\%) and mesioangular (32\%) impactions compared to distoangular $(21.9 \%)$ or vertical $(12.8 \%)$ impactions $(\mathrm{p}<0.001)$. It was significantly related to bone removal ( $\mathrm{p}<0.001)$ and tooth sectioning $(\mathrm{p}<0.001)$, and operation time was significantly longer $(\mathrm{p}<0.001)$ when lingual retraction was performed $(18.1 \pm 10.96 \mathrm{~min}$ compared to $9.1 \pm 7.64 \mathrm{~min})$. Bleeding into the socket was more likely with horizontal $(12.9 \%)$ or mesioangular (5.4\%) impactions than with distoangular $(0 \%)$ or vertical $(1.2 \%)$ impactions $(\mathrm{p}=0.01)$. Equally, bleeding occurred more commonly when bone removal $(\mathrm{p}=0.02)$ or tooth sectioning $(\mathrm{p}=0.004)$ was performed. Likewise, operations complicated by bleeding were significantly longer, $23.2 \pm 14.0 \mathrm{~min}$, compared to $10.9 \pm 8.85 \mathrm{~min}(\mathrm{p}<0.001)$ when there was no bleeding.

\section{Discussion}

Mandibular M3 surgery accounts for a significant proportion of iatrogenic injury to the LN $[12,14]$. Sensory impairment following this surgery is probably the most significant morbidity [2], but this is largely preventable if the potential risk is anticipated and the surgical procedure adapted accordingly. Despite numerous publications and suggested recommendations, there is no significant decrease in the number of cases of permanent LN 
Table 3. Association between the various variables and lingual hypoesthesia

\begin{tabular}{|c|c|c|}
\hline & \multicolumn{2}{|c|}{ Hypoesthesia } \\
\hline & $\mathrm{n}$ & $\mathrm{p}$ \\
\hline Age & & $0.59^{\mathrm{a}}$ \\
\hline Gender & & $0.52^{\mathrm{b}}$ \\
\hline Male & $2(1.4)$ & \\
\hline Female & $9(3.0)$ & \\
\hline M3 side & & $0.96^{\mathrm{c}}$ \\
\hline Right & $6(2.4)$ & \\
\hline Left & $5(2.5)$ & \\
\hline Anesthesia & & $0.38^{\mathrm{b}}$ \\
\hline Local & $0(-)$ & \\
\hline Local + sedation & $11(2.8)$ & \\
\hline Angulation & & $0.01^{\mathrm{c}}$ \\
\hline Mesioangular & $5(2.5)$ & \\
\hline Distoangular & $1(1.4)$ & \\
\hline Vertical & $1(0.8)$ & \\
\hline Horizontal & $4(10.0)$ & \\
\hline Level of impaction & & $0.06^{\mathrm{c}}$ \\
\hline Soft tissue & $0(-)$ & \\
\hline Partial bony & $9(3.5)$ & \\
\hline Total bony & $2(4.9)$ & \\
\hline Number of roots & & $0.41^{\mathrm{c}}$ \\
\hline 1 & $0(-)$ & \\
\hline 2 & $7(4)$ & \\
\hline Multiple & $3(7.1)$ & \\
\hline Shape of roots & & $0.81^{\mathrm{b}}$ \\
\hline Straight & $3(3.2)$ & \\
\hline Curved & $5(3.8)$ & \\
\hline Bone removal & & $0.02^{\mathrm{b}}$ \\
\hline No & $0(-)$ & \\
\hline Yes & $11(3.6)$ & \\
\hline Tooth sectioning & & $0.02^{\mathrm{b}}$ \\
\hline No & $4(1.3)$ & \\
\hline Yes & $7(5.7)$ & \\
\hline Lingual flap retraction & & $<0.001^{\mathrm{b}}$ \\
\hline No & $1(0.3)$ & \\
\hline Yes & $10(9.1)$ & \\
\hline Bleeding into the socket & & $0.008^{b}$ \\
\hline No & $8(2.7)$ & \\
\hline Yes & $3(23.1)$ & \\
\hline Operation time & & $0.001^{\mathrm{a}}$ \\
\hline Surgeon & & $0.39^{c}$ \\
\hline 1st- or 2nd-year resident & $0(-)$ & \\
\hline 3 rd- or 4 th-year resident & $3(1.7)$ & \\
\hline Specialist & $8(3.7)$ & \\
\hline
\end{tabular}

Values in parentheses denote percentages.

${ }^{a}$ t test. ${ }^{b}$ Fisher's exact test. ${ }^{c} \chi^{2}$ test.
Table 4. Stepwise logistic regression modeling for lingual hypoesthesia

\begin{tabular}{lllll}
\hline & $\begin{array}{l}\text { Regression } \\
\text { coefficient }\end{array}$ & $p$ & OR & $\begin{array}{l}\text { Confidence limits } \\
\text { for OR }\end{array}$ \\
\hline $\begin{array}{c}\text { Lingual flap } \\
\text { retraction }\end{array}$ & 3.128 & 0.003 & 22.821 & $2.833-183.827$ \\
$\begin{array}{c}\text { Bleeding into } \\
\text { the socket }\end{array}$ & 1.920 & 0.020 & 6.823 & $1.350-34.497$ \\
\hline
\end{tabular}

involvement $[5,7,8,14-16]$. The prevalence of postoperative lingual sensory impairment in our study compares favorably with other data from previous studies $[6,7,15$, 17]. We believe that temporary sensory impairment usually subsides within a 6-month period; longer impairment could be regarded as permanent $[5,13,17,18]$.

Patients' age had no influence on the incidence of nerve injury, this is in accordance with previous reports $[6,7,13]$ but different from others $[3,5,15]$, probably indicating that prophylactic removal of M3 is not justified. As previously reported, gender was not a predisposing factor for nerve injury $[5,15]$. Horizontal followed by mesioangular angulations, bone removal, tooth sectioning and longer operations were significantly related to LN morbidity as confirmed by previous data $[6,7,15]$.

A recent study [7] on mandibular M3 surgery without lingual retraction showed a higher prevalence of temporary and permanent LN damage $(6.5 \%$ and $1 \%$, respectively). Previous studies reported a higher sensory deficit in the trainee groups, suggesting surgical inexperience as a risk factor [5, 6]. However, in this study surgical experience was not a risk factor possibly due to the specialists' supervision. Lingual flap retraction is a controversial issue; whereas some discourage its use [19-21], others advocate it $[5,8]$. Lingual retraction per se was the strongest predictor of developing temporary postoperative hypoesthesia in this study, presumably a stretch-type injury from the retractor; $91 \%$ of patients who suffered sensory impairment had undergone lingual tissue retraction. Recent publications $[5,8,19]$ reported temporary LN deficit of $2.1-9.1 \%$ with lingual retraction. The decision to use this technique during surgery was mostly made with horizontal followed by mesioangular impactions, and with certain operative variables: tooth sectioning, bone removal and long operations. Careful lingual retraction in selected cases improved surgical access, and this could be responsible for the protection of the LN against permanent damage $[8,22]$. Intraoperative $\mathrm{LN}$ damage was not 
noted in this study; however, more studies are required to identify cases that require elective lingual protection at the start of surgery to eliminate any chance of bias resulting from potential damage to the nerve prior to passing the retractor during surgery. Unjustified use of retraction is responsible for a high prevalence of temporary sensory impairment [17, 21].

Regarding bleeding into the socket during surgery, the prevalence of this operative variable was low (2.9\%). Its occurrence does not necessarily indicate trauma to the inferior alveolar canal [7] as labial sensory deficit was not detected in any of the cases. However, it could be caused by fracture or perforation of the lingual plate by drills or instruments, with subsequent damage incurred upon the LN [15].

\section{Conclusion}

This study demonstrates that operative factors are the strongest predictors of temporary LN damage. However, the careful use of lingual retraction in selected cases could be responsible for protection against permanent nerve damage.

\section{References}

$>1$ Yuasa H, Sugiura M: Clinical postoperative findings after removal of impacted mandibular third molars: prediction of postoperative facial swelling and pain based on preoperative variables. Br J Oral Maxillofac Surg 2004;42:209-214.

-2 Visintini E, Angerame D, Costantinides F, Maglione M: Peripheral neurological damage following lower third molar removal: a preliminary clinical study. Minerva Stomatol 2007;56:319-326.

$\checkmark 3$ Chiapasco M, de Cicco L, Marrone G: Side effects and complications associated with third molar surgery. Oral Surg Oral Med Oral Pathol 1993;76:412-420.

4 Middlehurst RJ, Barker GR, Rood JP: Postoperative morbidity with mandibular third molar surgery: a comparison of two techniques. J Oral Maxillofac Surg 1988;46:474476.

5 Gülicher D, Gerlach KL: Sensory impairment of the lingual and inferior alveolar nerves following removal of impacted mandibular third molars. Int J Oral Maxillofac Surg 2001;30:306-312.

6 Valmaseda-Castellón E, Berini-Aytés L, Gay-Escoda C: Lingual nerve damage after third lower molar surgical extraction. Oral Surg Oral Med Oral Pathol Oral Radiol Endod 2000;90:567-573.
7 Jerjes W, Swinson B, Moles DR, El-Maaytah M, Banu B, Upile T, Kumar M, Al Khawalde M, Vourvachis M, Hadi H, Kumar S, Hopper $\mathrm{C}$ : Permanent sensory nerve impairment following third molar surgery: a prospective study. Oral Surg Oral Med Oral Pathol Oral Radiol Endod 2006;102:e1-e7.

$>8$ Pogrel MA, Goldman KE: Lingual flap retraction for third molar removal. J Oral Maxillofac Surg 2004;62:1125-1130.

$>9$ Sunderland S: A classification of peripheral nerve injuries producing loss of function. Brain 1951;74:491-516.

10 Loescher AR, Smith KG, Robinson PP: Nerve damage and third molar removal. Dent Up date 2003;30:375-380, 382.

11 Rehman K, Webster K, Dover MS: Links between anaesthetic modality and nerve damage during lower third molar surgery. $\mathrm{Br}$ Dent J 2002;193:43-45.

12 Hillerup S, Stoltze K: Lingual nerve injury in third molar surgery. 1. Observations on recovery of sensation with spontaneous healing. Int J Oral Maxillofac Surg 2007;36:884889.

13 Queral-Godoy E, Figueiredo R, ValmasedaCastellón E, Berini-Aytés L, Gay-Escoda C: Frequency and evolution of lingual nerve lesions following lower third molar extraction. J Oral Maxillofac Surg 2006;64:402-407.

14 Hillerup S: Iatrogenic injury to the inferior alveolar nerve: etiology, signs and symptoms, and observations on recovery. Int J Oral Maxillofac Surg 2008;37:704-709.

15 Renton T, McGurk M: Evaluation of factors predictive of lingual nerve injury in third molar surgery. Br J Oral Maxillofac Surg 2001;39:423-428.
16 Bataineh AB: Sensory nerve impairment following mandibular third molar surgery. J Oral Maxillofac Surg 2001;59:1012-1017.

17 Pichler JW, Beirne OR: Lingual flap retraction and prevention of lingual nerve damage associated with third molar surgery: a systematic review of the literature. Oral Surg Oral Med Oral Pathol Oral Radiol Endod 2001;91:395-401.

18 Robinson PP, Loescher AR, Yates JM, Smith KG: Current management of damage to the inferior alveolar and lingual nerves as a result of removal of third molars. Br J Oral Maxillofac Surg 2004;42:285-292.

19 Gomes AC, Vasconcelos BC, de Oliveira e Silva ED, da Silva LC: Lingual nerve damage after mandibular third molar surgery: a randomized clinical trial. J Oral Maxillofac Surg 2005;63:1443-1446

20 Gargallo-Albiol J, Buenechea-Imaz R, GayEscoda C: Lingual nerve protection during surgical removal of lower third molars: a prospective randomised study. Int J Oral Maxillofac Surg 2000;29:268-271.

21 Shepherd JP: Lingual nerve retraction increases the risk of temporary lingual nerve damage during mandibular third molar surgery. Evid Based Dent 2006;7:47.

-22 Gibbons AJ, Moss CE: Lingual flap retraction in third molar surgery. J Oral Maxillofac Surg 2007;65:364. 